\title{
Correspondence
}

\section{Response to Buckle}

SIR

Stephen Buckle's insistence on the fundamental similarity of processes and events in his article Biological processes and moral events (1988; 14:144-147), for all its instructiveness, wholly misses the point of the Australian Senate Select Committee's pronouncements on the question of the proper characterisation of the process of embryonic development (1). For Dr Buckle confuses events qua biological/factual occurrences and events qua 'morally significant markers'; and although the latter are his (and the Senate Select Committee's) ultimate concern, he proposes an analogy, viz the processcum-event of kicking a football, which concerns only a factual occurrence and is thereby singularly unhelpful in illuminating the question of our proper moral concern for the embryo.

There is nothing in the Senate Select Committee's report to suggest the belief that a biological process, being continuous, excludes the possibility of there being distinct events occurring during that process, or that the process in its entirety can properly be regarded as one big event. Nor is it evident that the committee, in preparing its report, was labouring under a philosophical confusion over whether a simple event like the kicking of a football could not also be regarded, with the help of a slow-motion camera, as a process. Rather, it asserts that the very continuity of early human development, with its profound complexity and fine-tuning, features which it does not take a slow-motion camera to reveal, precludes the stipulation that any particular event within that process, such as syngamy, implantation, the development of sentience, viability, etc, should be regarded as any more morally significant than any other, at least as far as non- therapeutic experimentation and destruction are concerned. The fact that the committee concludes thus demonstrates that it is not as confused as Dr Buckle thinks about the proper characterisation of events and processes; for clearly, in denying the special moral significance of various events in the life of the early human being, and their concomitant stages, it accepts that, as a matter of fact, they obtain.

Therefore, the central argument from analogy proposed by Dr Buckle misses the point of the debate. The inference he draws from it is that, given that individuable events do obtain during early human development, the possibility is left open that some of these might be more 'morally significant' than others; his own favourite might be, say syngamy. What I claim is that his inference concerning the possibility of morally significant events should have been the premise of his argument, and that he should have been engaged in showing that there are such events, for good philosophical and empirical reasons. This is what the Senate Select Committee, in its wisdom, and after hearing much evidence, denied; and for Dr Buckle merely to gainsay its conclusion, while spuriously attributing to it an elementary conceptual confusion, is not to advance the debate.

I might add that I find Dr Buckle's 'best solution' to the 'problem' of what fertilisation is wholly implausible. Fertilisation is uncontentiously regarded by most people as the event constituted by the penetration of the ovum by the sperm. Given that penetrating the egg might take the sperm several hours, how does this licence the inference that 'fertilisation is that causal sequence beginning when the sperm succeeds in penetrating the egg, and ending when syngamy is complete' ( $p$ 145), ie fifteen days later? Dr Buckle has offered no argument for this conclusion. Indeed, he says that 'to conclude thus is, in the first place, to propose a convention to govern the proper employment of a term in our language, not to insist on an obvious matter of fact'. Moreover, such a proposal goes against the very tenor of Dr Buckle's article, with its emphasis of the point that events can be individuated even though they can often also be regarded as processes: why then should we regard the event of fertilisation as taking fifteen days simply because penetration of the ovum is not instantaneous? It seems then that it is Dr Buckle, not the Senate Select Committee, who is confused as to the inferences to be drawn from a consideration of events and processes. It is this distortion of our ordinary language and of our ordinary understanding of terms such as 'fertilisation', in order to justify certain moral ends, against which we should be vigilant.

\section{References}

(1) Senate Select Committee on the Human Embryo Experimentation Bill 1985. Human embryo experimentation in Australia. Canberra: Australian Government Publishing Service, 1986.

DAVID S ODERBERG Wolfson College Oxford, OX2 6UD

\section{To tell or not to tell the diagnosis of schizophrenia}

\section{SIR}

I find myself having to put pen to paper in reaction to Jacqueline Atkinson's paper in the Fournal of Medical Ethics March 1989, entitled To tell or not to tell the diagnosis of schizophrenia. 
I have several points to make: 1 . The author describes the individuals' rights to truth and information and maintains that one of the arguments for not telling 'is the uncertainty principle'. This refers to the fact that a doctor can never entirely be sure of the diagnosis or prognosis but yet the author goes on to say that the information conveyed to the patient must be based on knowledge and experience rather than abstract and absolute truth. I find this rather a contradiction.

2. The author states that telling someone she has schizophrenia gives her both an explanation of her behaviour and a reason for it, which in my own opinion is not valid. The term schizophrenia is a label. It is a label which individual psychiatrists, doctors and the general public use. It has different meanings for different people. Even within the group of psychiatrists that practise, for example in the United Kingdom, the term schizophrenia will mean different things to each one.

3. In relation to point $2 \mathrm{I}$ find it difficult to make sense of the paper without any reference to diagnostic criteria such as the Diagnostic and Statistical Manual of Mental Disorder, Third Edition, Revised (DSM-III-R). The author regards other terms such as 'nervous breakdown' and 'problems with your self-confidence' as vague and meaningless phrases. My contention would be that using the term schizophrenia without specifying which diagnostic criteria one is using is equally vague and meaningless in terms of planning for the future and managing the individual's behaviour. For example using the International Classification of Diseases 9th Revision, (ICD-9) an individual can be diagnosed as having schizophrenia on a first episode of psychotic symptoms. At that point informing patients they have schizophrenia would be valid if one was using ICD-9 but would in most psychiatrists' opinion be meaningless in terms of prognosis, outcome and how best to manage the symptoms or behaviour. In contrast, using DSM-III-R, the diagnosis of schizophrenia cannot be made until an individual has had continuous symptoms for over six months. Informing a patient that she has a diagnosis of schizophrenia under DSM-III-R, is relatively more meaningful in terms of prognosis etc.

4. It would be my contention that the diagnosis, ie the label, is completely irrelevant. What is relevant is the level of distress and disruption in the individual's life which is caused by whatever symptoms she is experiencing. These are problems. In fact the patient may not be aware or fully aware of the results in her general life of having these symptoms. It would be my contention that it is this sort of information which needs to be imparted to the patient.

5. The author describes psychiatrists as lying to patients through an act of omission by not telling them their diagnosis. The author very rightly mentions the social effects of being labelled schizophrenic, and that being given the label of schizophrenia may do harm within the individual's social setting. But she feels that the concern for its harmful social affects are out of proportion as the individual is under no obligation to share the information of her diagnosis with others but yet in the same paper she uses the example of an individual who heard on the television that a certain depot injection was used for schizophrenics and psychopaths. That individual then made the assumption that he had schizophrenia. Also, the author in her case history very clearly describes a young man who had a diagnosis of schizophrenia but had not been informed of it, who then subsequently found out his diagnosis through the Job Centre. This highlights one of the issues involved which is that once one has this label of schizophrenia agencies have access to one's medical records and that once the label is used it in effect cannot be reversed so although the patient himself may not want to share the information about his diagnosis with other people, other people may in fact discover the label through independent means.

I must say, after these criticisms, that I agree with the main gist of $\mathrm{Dr}$ Atkinson's paper that patients have a right to be informed. I think the crux of the matter is, or rather the question to be asked is, what exactly is it that they need to know? The studies which she? has quoted regarding the prognostic $\overrightarrow{\vec{F}}$ factors associated with schizophrenia she describes as 'very real evidence we? have regarding outcome and particular variables'. It must be stated that these $\frac{\bar{s}}{\sim}$ variables have been derived through $\mathbb{\varnothing}$ statistical analysis and as such oneo cannot and should not generalise them to an individual patient and that using $\vec{O}$ these variables does not give one carte blanche to predict the future.

PETER DONNELLY

Senior Registrar in Psychiatry, West Glamorgan Health Authority

\section{Killing and voluntary euthanasia \\ SIR}

In the Words item by Jean Davies, entitled Raping and making love are different concepts: so are killing ant voluntary euthanasia $(1988 ; 14: 1800$ 149), I like the analogy of murder.v voluntary euthanasia with rape $\frac{0}{3}{ }^{\circ}$ making love, since rape is likewises without consideration for the victim.

However, I cannot agree that the basic distinction between murder ando voluntary euthanasia is killing rathes than helping to die. In carrying oup euthanasia it may be necessary, wher ${ }^{3}$ natural death is not imminent, actualle to kill - for example if the patient is . incapable of any active participation and certainly in the case of infan? euthanasia - but, provided the killing were a compassionate act, carried oup. for the sake of the patient and fog sufficient reason, it would surely still be euthanasia (whether voluntary or nonvoluntary), not murder. The word 'kilp may well have unfortunate associations 8 but that does not justify replacing it be less apposite words.

BARBARA SMOKESO 6 Stanstead Grove London SE6 4UIु 